\title{
LA VIDA FEMENINA A TRAVÉS DE LA MIRADA DE LOS ESCRITORES VIAJEROS EN ARGENTINA (1909. 1914): MANIFESTACIONES Y TRANSFORMACIONES
}

\author{
Laura Giaccio ${ }^{85}$
}

RESUMEN: En este artículo examinamos cómo se caracterizó la mujer argentina y su vida diaria por la pluma de algunos escritores que viajaron a Argentina desde Europa en el periodo 1909-1914. El objetivo del análisis es tratar de vislumbrar, a través de los ojos del viajero, la sensibilidad que gobernó sobre el femenino en la sociedad de Buenos Aires, especialmente en relación con su vida intelectual y artística en un momento de transformación de sentimientos como era al comienzo de siglo XX. Para ello, se considera que las representaciones detalladas de mujeres argentinas fueron mediadas por una mirada masculina, inmerso en una determinada concepción de la vida femenina.

Palabras clave: viajantes - representaciones - sensibilidad - vida femenina

RESUMO: Neste artigo examinamos como foi caracterizada a mulher argentina e sua vida diária pela pena de alguns escritores que viajaram para a Argentina da Europa no período 1909-1914. O objetivo da análise é tentar vislumbrar, através do olhar do viajante, a sensibilidade que governou sobre o feminino na sociedade de Buenos Aires, especialmente em relação à sua vida intelectual e artística, em um momento de transformação de sentimentos como era no início do século XX. Para fazer isso, consideramos que as representações detalhadas de mulheres argentinas foram mediadas por um olhar masculino, imerso em uma certa concepção da vida feminina.

Palavras-chave: viajantes - representações - sensibilidade - vida feminina

Los relatos de viaje -en su considerable heterogeneidad- han sido utilizados para conocer tanto al "otro" como para conocernos a "nosotros" en otras épocas de nuestra historia. En las ciencias humanas, los relatos de

\footnotetext{
${ }^{85}$ Profesora en Literatura del Instituto de Investigaciones en Humanidades y Ciencias Sociales (UNLP-CONICET) y del Centro de Estudios de Teoria y Critica Literaria (CTCL). Bolsista de Doctorado.
} 
viaje, han sido considerados en su mayoría como fuentes a las que se recurrió y sigue recurriendo para comprender los modos de vida de los pueblos desde todas sus aristas y para conocer las diferentes formas de percepción de los viajeros.

Argentina ha sido el objeto principal de innumerables relatos de viaje. Viajeros españoles, ingleses, franceses, alemanes y norteamericanos han escrito y puesto en imágenes el pais a través de las largas décadas del siglo XIX. Estos viajeros tenían diversas profesiones: eran científicos, políticos, aventureros, comerciantes, empresarios, etc. El siglo XX también recibió a viajeros que llegaban desde otras partes del mundo. Hubo un momento especial en la afluencia de viajeros que se ocasionó en torno al Centenario, entre 1909 y 1914, cuando se produjo una concentración de visitas a Buenos Aires realizadas por escritores viajeros que llegaban especialmente desde España y Francia.

Anatole France, Vicente Blasco Ibáñez, Jules Huret y Enrique Gómez Carrillo fueron algunas de las figuras de relevancia cultural que llegaron a Argentina en este período, y que elaboraron textos sobre ella en diferentes formatos y géneros, como el relato de viaje, la conferencia, la entrevista, y el libro informativo-manual. Sus escritos dan cuenta de las múltiples miradas de los viajeros sobre el país pero, a pesar de que cada uno posase sus ojos en diferentes asuntos, podemos percibir que un tema de interés de todos ellos fue la mujer argentina y su vida.

En este trabajo examinaremos cómo fue caracterizada la mujer argentina y su vida cotidiana por la pluma de estos escritores viajeros provenientes de Europa. El objetivo del análisis será tratar de vislumbrar, a través del ojo del viajero, la sensibilidad que regía sobre lo femenino en la sociedad porteña, en especial, con respecto a su vida intelectual y artística, en un momento de transformación de los sentires como lo fue a principios del siglo XX. Para ello tendremos en consideración que las representaciones detalladas de la mujer argentina que llevaron a cabo los viajeros estuvieron mediadas por una mirada masculina, inmersa en una concepción determinada de la vida femenina. El corpus que se utilizará principalmente serán los relatos de viaje y algunas intervenciones de los escritores viajeros en la prensa periódica.

\section{La mujer argentina a través del ojo del viajero}

En la crónica titulada "Mi viaje a la Argentina", publicada en La Nación, semanas antes de su viaje, Blasco Ibáñez decía: "Del país argentino, 
lo que más me atrae como modelo de estudio, es la mujer" (IBÁÑEZ, 1909). Sabemos que Blasco Ibáñez tenía intenciones de escribir un libro sobre nuestro país para que Europa conociera a una de las naciones jóvenes América del Sur, por eso se transformó en un viajero-investigador y su mirada estuvo posada, sobre todo, en la mujer como un sujeto al que inspeccionó durante su estadía. ${ }^{86}$ Pero no sólo el escritor español estudió a la mujer argentina, sino que los demás viajeros también lo hicieron, ya que es una figura que aparece reiteradamente en los textos.

Pueden distinguirse tres cuestiones sobre la mujer en las intervenciones de los viajeros: en primer lugar, lo corporal, en segundo, lo mental y espiritual y, por último, su vida cotidiana.

\section{- LO CORPORAL: LA ELEGANCIA Y LA BELLEZA}

Antes de partir hacia nuestro continente, Blasco Ibáñez ya adulaba a la mujer argentina en La Nación:

Yo la he encontrado en París, en Londres, en Madrid y siempre me ha bastado una simple mirada al entrar en el teatro, en el restaurant o en el salón, para reconocerla al punto. [...] Cierto es que ayuda mucho para reconocerlas, su belleza especial y típica, su belleza aparte, que las distingue en un salón entre cien mujeres, y resalta sobre la hermosura de las europeas, más artificial y como fatigada. Es una belleza sana y fina que parece residir en causas internas más que en el adorno exterior. Los años parecen transigir a su vista quedándose a un lado encogidos, respetuosos y galantes. Tienen la frescura milagrosa, la juventud inalterable de su pueblo.

${ }^{86}$ En "Cómo ve Europa a América", La Nación (Buenos Aires), lunes 5 abril de 1909, Blasco Ibáñez daba cuenta de la ignorancia de los europeos con respecto a lo que era América y de cómo la literatura francesa habia incidido en el imaginario sobre nuestro continente. Por este motivo, decide emprender la escritura de un libro sobre nuestro pais. Un año más tarde, en el prólogo de La Argentina y sus grandezas (Valencia: Prometeo, 1910), 3, decia: "como el autor, por ser europeo, conoce los extravíos de juicio del Viejo Mundo en su apreciación de los países sudamericanos -defectos de los que también participaba antes de visitar la tierra argentina en un viaje de observación-, su obra va encaminada a desvanecer preocupaciones, falsedades e ignorancias que casi han tomado el carácter de verdades indiscutibles". 
Pero con ser su belleza tan característica, lo que más llama la atención en la dama argentina y la hace ser reconocida en todas partes, es su elegancia; elegancia natural, personalísima, no aprendida. (IBÁÑEZ, 1909, s/p.)

Con un discurso galante, Blasco Ibáñez se dedica a adular a la mujer argentina por su belleza y elegancia, tanto antes de conocerla en su tierra, como posteriormente lo hará en la "Enquête sobre la mujer argentina" realizada por André Ibels, que se publicaba en la revista Gustos y gestos. ${ }^{87}$ Para el escritor valenciano, "la dama argentina [...] es dechado no solo de elegancia y de buen tono sino también de dignidad personal, de pureza sin hipocresía, de corrección exquisita" (IBELS, 1910, s/p.). La entrevista finaliza con un breve diálogo en donde se muestra a un Blasco Ibáñez embelesado por las mujeres argentinas:

-Me parece querido amigo que viene U. enamorado de aquella tierra... ¿No será alguna porteña en particular la que lo ha conquistado a U.?...

Blasco Ibáñez se echó a reír.

-No -exclamó- no, no es de una porteña de quien estoy prendado sino de todas juntas. A mi edad, casado, con hijos no tengo derecho a fijarme en las señoritas sino con ojos desinteresados de artista... pero es cierto que...

¿QQué?...

-Que si no se tratara de mí sino de un amigo que fuera mozo y soltero y que quisiera casarse y ser feliz, yo le aconsejaría que se fuera a la Argentina para tratar de buscar una

\footnotetext{
${ }^{87}$ La revista Gustos y gestos. Artístico, Literario, Modas y Actualidades era una publicación ilustrada dedicada a la mujer con sede en Paris, que apareció en 1910. Su director era Leo Merelo. Alli se publicaban notas de moda, decoración, cosmética, reseñas de obras teatrales protagonizadas por mujeres, retratos de mujeres famosas, consejos, etc. Asimismo, aparecian publicidades de temas de interés de la mujer tanto de tiendas de Argentina y de Francia. Esta publicación pensaba a sus receptoras como mujeres argentinas de la aristocracia que tenian la posibilidad de viajar a Europa y realizar estancias en París. La revista también tenía un sector literario donde publicaban solamente hombres como Manuel Ugarte, Enrique Gómez Carrillo, Alejandro Sux, Henri Barbuse, Rubén Dario, Rufino Blanco Fombona, entre otros. Una sección de la publicación fue la "Enquête sobre la mujer argentina". Alli fueron entrevistadas figuras masculinas francesas e hispanoamericanas donde se les preguntaba sus consideraciones sobre la mujer argentina.
} 
compañera ideal ¡Son tan lindas!... ¡Y parecen tan buenas! (IBELS, 1910, s/p.)

Anatole France, entrevistado también en la "Enquête sobre la mujer argentina" de Gustos y gestos alababa la figura de la mujer con un estilo recargado:

Son muy deliciosas, hospitalarias y alegres. Su elegancia, ¡quién lo duda! Vale más que la nuestra... porque alli todas las mujeres, son soberanamente bellas. En sus ojos soñadores y de aterciopeladas pestañas, existen caricias y languideces que no se encuentran ni se conciben en nuestros climas algo menos templados que los de la hermosa América. Agregad a esto su gracia nativa y la flexibilidad en toda ella... He aquí la mujer en toda su esplendente belleza. Además, sabe elegir en nuestras modas la parte que le es necesaria para no presentarse ridículamente; es demasiado artista para esto, $¡ O h$, son adorables Thaïs de la Argentina! (IBELS, 1910, s/p.)

Por su parte, Jules Huret, en su libro La Argentina. De Buenos Aires al Gran Chaco, también registró con su mirada la apariencia de la mujer argentina:

El lujo de las mujeres es extraordinario y su belleza sin igual. Puede preferirse, ciertamente, la ágil elegancia natural de las americanas del Norte o la gracia coqueta de las francesas, pero es imposible ver caras más bonitas que las que se ven en los lujosos coches del parque de Palermo. Mujeres jóvenes de tez mate, de grandes y ardientes pupilas, de rasgos regulares y finos pero inmóviles, de una expresión grave; jóvenes vírgenes de mirada sin timidez y discreta sonrisa, hacen pensar en las bellezas encogidas, enclaustradas en los misteriosos harenes de los reyes árabes que, por un milagro enloquecedor se quitasen súbitamente el velo, para vuestra perdición. Su gracia encantadora, la pasión contenida y tímida de sus gestos y, sobre todo, el fuego profundo de aquellas miradas en aquellas fisonomías serias y 
concentradas, despiertan en el corazón del paseante extranjero a la hora del corso de Palermo, ensueños de voluptuosidad intensa y religiosa, que le será preciso apagar pronto (HURET, 1911, p. 95-96).

Como puede observarse, en las citas escogidas, la moda y la elegancia son aspectos que se repiten a la hora de describir a la mujer porteña. Los relatos de viaje de Huret, Gómez Carrillo y Blasco Ibáñez, instalan, además de la mujer, a otra protagonista indiscutible de Argentina: la ciudad de Buenos Aires. La mujer y Buenos Aires conforman una dupla que se caracteriza por la belleza y el lujo. Podría pensarse que el lujo en la indumentaria y en los accesorios que llevaba la mujer de la aristocracia porteña combina con la modernización y embellecimiento de la ciudad, momento en el cual Buenos Aires se instauraba como una capital cosmopolita. Esos esplendores de la ciudad también se manifestarán en la figura femenina que delinean los viajeros. Gómez Carrillo describe asombrado el lujo que desbordaba de las tiendas de la calle Florida, sólo para adornar a la mujer:

No es la riqueza lo que a mí me pasma; es el buen gusto, el refinamiento, el supremo chic. Todas las piedras preciosas están ahí; pero no cual en los escaparates de Nueva York, ostentando sus quilates con la enorme grosería de su precio, no, sino como excusando su valor de mercadería entre las gracias artísticas de sus engarces. Los Lalique, los Brindeau, los Tiffani, los magos de la joyería, parecen haber escogido estas vidrieras para exponer sus más perfectas obras.

Y no son sólo los objetos de oro los que aquí merecen el nombre de joyas. Cada deventure representa un joyel. [...] esos encajes, son joyas, esos zapatitos minúsculos, que yo querría tener en mi mesa de trabajo para llenarlos de flores como búcaros de seda, son joyas... (GÓMEZ CARILLO, 1914, p. 57-58)

El lujo que Gómez Carrillo refiere, lo seguirá observando en toda la ciudad, no sólo en sus tiendas, sino también en su arquitectura, en sus paseos, en sus teatros: 
América, encarnada en su metrópoli argentina, no tiene hoy, estéticamente nada que envidiar. Sólo que icómo hacer comprender tal verdad a Europa? Yo mismo confieso con rubor que, cuando Rubén Darío me pronunciaba largos discursos familiares sobre el refinamiento de Buenos Aires, no podía dejar de pensar que todo aquello era una gentil exageración de poeta (GÓMEZ CARILLO, 1914, p. 59).

Cabe destacar que estos escritores se relacionaron exclusivamente con la aristocracia argentina, de allí que sus descripciones de la mujer sean de las que accedian a las novedades europeas de la moda y la cosmética, las que podian realizar el grand tour, y las que paseaban por los parques de Palermo y la calle Florida en vehículo. En suma, las que disfrutaban de una vida acomodada y cosmopolita.

En las descripciones de la mujer porteña delineadas por Huret, Blasco Ibáñez y France aparecen dos términos que se repiten: elegancia y belleza. Esa forma de caracterizarla resuena en las palabras de Gómez Carrillo cuando habla de Buenos Aires:

La superioridad de Buenos Aires, cuando se la compara con las ciudades nuevas, con Berlín, con Montreal, con Nueva York, está en su gusto, que sabe tal vez más por instinto que por estudio, suavizar lo que hay demasiado luciente y velar lo que hay de demasiado lujoso en su joven belleza (GÓMEZ CARILLO, 1914, p. 31-32; subrayado mío).

De manera que, en los textos nos encontramos con la dupla mujer argentina y Buenos Aires con dos rasgos específicos: la belleza y la elegancia. Este par, pone en evidencia una doble mirada eurocéntrica de los viajeros en la que se reproduce la desigualdad: la mujer es observada por un hombre, y la ciudad, es decir, Latinoamérica, es examinada por un europeo. Observamos un modo de describir marcado por un discurso donde el sujeto y el objeto -la mujer y la ciudad, respectivamente- son doblemente menores jerárquicamente del que escribe. En estos casos, el viajero europeo se sitúa en un lugar de superioridad con respecto a lo que observa.

En resumen, en las citas escogidas se distingue que el discurso de los escritores viajeros se repite, es decir, se halaga y lisonjea a la mujer argentina. Si bien, pareciera que hubiera una mirada más bien superficial 
de los viajeros, no podemos dejar de decir que también percibieron otros asuntos de la mujer, como su mentalidad y espiritualidad.

\section{- LA MENTALIDAD Y ESPIRITUALIDAD FEMENINA}

A pesar de que los ojos de Blasco Ibáñez estaban ciegos por la belleza de la mujer argentina, también pudo vislumbrar la mentalidad femenina:

La argentina es tan elegante como la parisiense, y además no es la parisiense. Bajo los complicados adornos de la moda hay una mujer, una personalidad, un alma, no un maniqui movido por frivolos resortes (IBELS, 1910, s/p.; subrayado mío).

De allí que aparezcan también descripciones sobre su carácter, su pensamiento y su concepción de los asuntos de la vida. Blasco trata de enaltecer la figura femenina presentándola con una multiplicidad de aptitudes espirituales: "La argentina llama la atención entre las mujeres europeas por su cultura, sus gustos artísticos, sus exquisiteces de alma [...] la mujer estudia, ama las artes y conserva en el hogar una llama de poesía sentimentalismo, como la hembra de remotos tiempos guardaba el tizón sagrado, fuente de vida" (IBÁÑEZ, 1909, s/p.). Para los viajeros provenientes de Europa, la argentina en el trato social era sencilla, digna, pura, correcta, fina en los modales... Esas eran las cualidades de la "mujer ideal" concebida por el hombre burgués.

Jules Huret fue el que realizó una observación más aguda sobre el tema, en especial sobre los intereses intelectuales de la mujer:

Las mujeres están dotadas de una gran finura de modales, de una amable sencillez y de una viveza de espíritu perfectamente comparables con las de nuestras más brillantes parisienses.

Sobre un velador, al lado del estuche de los labores de la señora R. M...., vi las últimas publicaciones filosóficas de la colección Alcan y del Mercurio de Francia (HURET, 1911, p. 16-17).

Esta es la primera ocasión en sus libros en la que Huret da cuenta de uno de los aspectos más reservados de la mujer, como lo era su inclinación intelectual. La discreción se debía a las privaciones que tenía la 
mujer, en especial si estaba casada, ya que debía dedicarse al hogar y a sus hijos. José Pedro Barrán hace referencia a las dos caras del pudor femenino, que se identificaba como una virtud de las tantas que debía tener la mujer del novecientos rioplatense. Una de esas caras era la modestia, que incluía la vestimenta, "pero sobre todo atañía al alma y el encubrimiento de las dotes intelectuales, el huir de toda esa afectación y sumirse en el silencio o la conversación llana pues la mujer 'sabihonda' era 'varona' y desagradable al hombre por querer competir con él” (BARRÁN, 2015, p. 352). Huret observa esta situación, pero también percibe en el ambiente un leve cambio con respecto a estas privaciones:

Hay excepciones, ciertamente, y son bastante numerosas, pero, ¿cómo son juzgadas? Algunas mujeres comienzan, tímidamente, como temiendo llamar la atención, a discutir entre ellas de arte o de literatura. Pero en seguida son tachadas de bas bleus. Y otras, que se suscriben a las Revistas de Arte, que hablan de educación a propósito de sus hijos, son tachadas inmediatamente de pedantismo. Pero hay espíritus emancipados, que desafían la opinión y se burlan de esas críticas pueriles, y, a veces, se experimenta la alegre sorpresa de encontrar, en contraste con esa apatía intelectual, una mujer de rara inteligencia, que discute sobre historia, filosofía o sociología con la rectitud lógica y la sutilidad de las finas inteligencias latinas (HURET, 1911, p. 50-51).

Esta mujer de la que habla Huret era la que pertenecía a la aristocracia porteña, la que se cultivaba en su hogar y a la cual el escritor distinguió de la de la clase media, que también se preocupaba por su educación, ya en su caso, en instituciones de enseñanza:

Entre la clase media, en la nueva generación, que se emancipa poco a poco de las antiguas tradiciones, se observa ya un deseo de cultura, una curiosidad hacia las ideas y tendencias positivas, a emanciparse de las antiguas costumbres, las escuelas normales del Estado y las facultades de la enseñanza superior, comienzan a producir mujeres 
profesores, médicos y artistas de ese sexo (HURET, 1911, p. 54).

Lo interesante de los libros de Huret, es que registran no sólo sus observaciones, sino también conversaciones con sus anfitriones. En el primer capítulo de La Argentina. Del Plata a la Cordillera de los Andes, titulado "La sociedad", aparece en discurso directo una voz femenina que dialoga con el viajero sobre la reducida sociabilidad, especialmente, con respecto a las reuniones en las casas familiares ella sostiene:

Además, en todos los países fueron las mujeres las que impusieron la moda y crearon las prácticas de la vida de sociedad. Pero la estrechez de la vida familiar y el puesto que se las asigna en el matrimonio y en la sociedad, han hecho aquí que estén mal preparadas para ese papel de iniciadoras. ¿Qué parte puede tomar en la vida de sociedad una mujer que durante quince años se ve embargada enteramente por maternidades sucesivas y el cuidado exclusivo de sus hijos? (HURET, 1911, p. 25)

Este comentario realizado por una mujer de la aristocracia da cuenta de cómo se sentían las mujeres con respecto a sus horizontes de expectativas, no sólo en lo relacionado con las reuniones sociales, sino que se podría extender a todos sus aspectos de la vida. En la conversación se contempla, por un lado, el conocimiento que tenía la mujer argentina del lugar que ocupaba la mujer europea en la población y, por otro lado, un interés por discutir sobre cuestiones serias como lo era el rol de la mujer en la sociedad, que es tematizado por la propia mujer que dialoga con Huret. A pesar de que la mujer debía tener una conversación llana y ser modesta con sus virtudes intelectuales, encontramos este tipo de diálogo más privado, con el viajero como confidente, no sometido a los condicionamientos sociales, donde se muestran los sentires de la mujer.

Nuevamente en los escritos de Huret podemos trazar un paralelismo entre la mujer y Buenos Aires. Según Margarita Pierini (2008), en los libros del escritor francés, el rasgo esencial con el que caracteriza la ciudad capital es el cambio, la transformación. Ese mismo rasgo es el podría aplicarse a la situación de la mujer con respecto a su afán de ampliar sus horizontes. Desde la perspectiva de Huret, Buenos Aires y la mujer están en proceso de 
transformación: la primera, de su exterior, de su apariencia, y la segunda, de su interior.

Los fragmentos citados manifiestan una mirada, la del viajero, que se percata de una experiencia social en proceso, debido a nuevos sentires en formación, tanto a través de sus observaciones como a través de conversaciones con hombres y mujeres. Estos leves cambios que se iban sucediendo, iban estableciendo nuevas maneras de concebir la vida cotidiana de la mujer, en especial lo relacionado con su instrucción ${ }^{88}$. Y partir de estas transformaciones, la mujer accedería de a poco a espacios que antes tenía vedados.

\section{- VIDA COTIDIANA Y ESPACIOS}

En El mal metafísico de Manuel Gálvez, novela en clave en la cual se describe el mundillo literario, periodístico y artístico de Buenos Aires a principios del siglo XX, Lita Itúrbide, una joven de la aristocracia que se relaciona con el protagonista, el escritor, Carlos Riga, desea poder acceder al café, espacio de sociabilidad que frecuentaban los escritores y periodistas para discutir sobre las novedades literarias. Pero por su doble condición de mujer y aristócrata, ese espacio está vedado para ella:

¿Serían como él [Riga] todos los literatos? ¡Qué lindo poder conocerlos! Le gustaría ir a esa célebre Brasileña que Riga nombrara varias veces, escuchar a Orloff, a Noulens, a Rueda, a Reina, y a otros, de quienes Eduardo contaba tantas cosas interesantes (GÁLVEZ, 1947, p.34).

Este fragmento da cuenta de la imposibilidad de las mujeres de poder a ingresar a algunos espacios de sociabilidad de la ciudad. La circulación de las mujeres por los espacios fue otro de los aspectos sobre el que pusieron atención Huret, Gómez Carrillo, Blasco Ibáñez y France

\footnotetext{
${ }^{88}$ Losada considera que la educación de las niñas de la alta sociedad puede haber desarrollado nuevas formas de concebir la vida femenina: "la educación impartida, tanto por sus contenidos por quienes la tenían a su cargo (escuelas e institutrices), podia moldear algo más que una niña casadera, a pesar de que ése fuera el horizonte convencional. Antes bien, la conjugación de institutrices algo descontracturadas, el roce cosmopolita y la educación en instituciones relativamente pluralistas (a pesar de su signo confesional), llegaron a revolucionar las expectativas de algunas niñas y a alentar transgresiones a las normas y valores que se pretendian arraigar" (LOSADA, 2008, p. 127).
} 
durante su estadia en Buenos Aires. Ellos colmaron sus páginas con comentarios sobre las actividades de la mujer y los espacios que podía frecuentar. El teatro Colón, los parques de Palermo, la calle Florida y la avenida Alvear, el Hipódromo eran algunos de los espacios públicos a los que la mujer accedía y sobre los cuales encontramos descripciones en los relatos de viaje. Los viajeros también escribieron sobre su tiempo de ocio: "además, en verano disfrutan de la famosa temporada de baños en Mar del Plata. Las regatas en las Islas del Tigre, Venecia americana con hoteles, clubes y restaurantes lujosos, son otra de sus diversiones" (IBÁÑEZ, 1910, p. 447).

La mayor ocupación de las mujeres aristocráticas, además de su casa, fue la beneficencia. Los asilos, los hospitales y los orfanatos fueron espacios donde ellas predominaban. Blasco Ibáñez y Huret pusieron su mirada sobre la Sociedad de Beneficencia, gran obra femenina, y le concedieron importancia con sus largas descripciones sobre este lugar y su función:

Pronto hará un siglo que existe esa obra exclusivamente femenina, y en ese tiempo no ha hecho sino adquirir importancia, siendo innumerables los beneficios que ha reportado. Se compone la Sociedad de unas 60 mujeres elegidas entre las familias más distinguidas de Buenos Aires, a las cuales confía el Estado -literalmente- la asistencia de los pobres y los enfermos (HURET, 1911, p. 102).

Este espacio donde la mujer detentaba un poder, era codiciado por el hombre que quería desligarla de su labor. Huret registra esta situación: "Ese monopolio femenino en el orden de la beneficencia es muy combatido [...] A algunos les parece poco razonable que las mujeres, declaradas 'menores' por la ley en lo que atañe a la administración de sus bienes, puedan disponer de millones que les son confiados por el gobierno y el público" (HURET, 1911, p. 103). Esto se relaciona directamente con el tema de la división de actividades en distintos espacios, unos para la mujer y otros para el hombre, que también fue observado por los viajeros:

El hombre es de conducta más ligera. La vida en el club, los teatros y otros centro de placer que importan cargamentos de mercería de Europa, quebrantan su fidelidad. La mujer cumple con más firmeza los compromisos contraídos. Se 
mantiene algo aislada del trato social, y si busca reuniones y fiestas, es con las de su sexo (IBÁÑEZ, 1910, p. 443).

Huret nuevamente registra la voz de la mujer quien le detalla minuciosamente esta fragmentación entre los sexos:

-Los hombres y las mujeres se ven, es verdad, pero separadamente. Los hombres se reúnen en el club o en sus tertulias para hablar de los sucesos políticos o de sus estancias, y las mujeres, por su parte, organizan bailes, tés, bridges y gardenparties de las que son excluidos los hombres. Además, las mujeres se visitan con frecuencia, reuniéndose las amigas por la noche, después de cenar, cuando los maridos se han marchado. Así, pues, fuera de la familia, se desliza divergentemente la existencia de los hombres y de las mujeres (HURET, 1911 (a), p. 26).

Si retomamos el tema que plantea la novela de Gálvez, la imposibilidad de la mujer de acceder a determinados lugares relacionados con la vida intelectual, en los textos de los viajeros se exhiben pequeñas transformaciones que se fueron produciendo en la sensibilidad con respecto a la vida femenina en la sociedad durante la primera década del siglo XX. En ellos se puede distinguir un germen de cambio impulsado por la aspiración de las mujeres por ingresar al mundo literario y artístico y a la educación formal en toda su extensión ${ }^{89}$. Blasco Ibáñez da cuenta de algunas acciones que llevaron a cabo las aristocráticas para acercar a la

\footnotetext{
${ }^{89}$ Como detalla Losada en La alta sociedad en la Buenos Aires de la 'Belle Époque'. Sociabilidad, estilos de vida e identidades, "no faltaron quienes rompieron con los horizontes convencionales de manera más pronunciada. Un buen ejemplo son las mujeres volcadas a las letras, si tenemos presento que lo bien visto era que las aptitudes culturales se restringieran a adornar las artes de la dama en el salón. En el novecientos la figura más sobresaliente en ese sentido fue Emma de la Barra [...] Un caso parecido fue el de Delfina Bunge. Cuando obtuvo un premio de poesía en francés a comienzos del siglo XX, su familia no consideró apropiado que saliera retratada escribiendo en Caras y caretas. Estos reparos son notables si tenemos en cuenta que Delfina provenia de una familia de intelectuales, como lo eran sus hermanos Carlos Octavio o Alejandro. A vuelta de página, su caso ilustra algo ya dicho: cómo la educación más refinada y cosmopolita que se extendió en la Belle époque, así como un entorno familiar que, aunque no lo pretendiera, sí podia propagar entre las mujeres de la casa intereses que iban más allá del perfil de esposa y madre, podian despertar inquietudes que trascendian las convenciones imperantes" (LOSADA, 2008, p. 134).
} 
mujer a estos espacios: "Un grupo de damas ha fundado una rica biblioteca para la educación femenil, organiza conferencias y celebra anualmente la "Fiesta del libro'" (IBÁÑEZ, 1910, p. 447). ${ }^{90}$ Cuando Huret explica las particularidades de la vida intelectual del país, manifiesta que hay "oasis delicados" donde se han desarrollado el conocimiento y la erudición. Para él, esos espacios son la universidad y algunos salones. Llama la atención que el escritor francés, que fue el viajero que tuvo una mirada más afilada, no haya incluido en esa lista, los momentos de intimidad femenina en la cual se le otorgaba tiempo a la lectura, tiempo en que la mujer podía formarse e informase de las novedades europeas.

Más allá de su posibilidad de cultivarse en la intimidad, la mujer no podía acceder a algunos espacios si tenía un interés intelectual, como por ejemplo a los cafés y redacciones de diarios. Estos espacios hasta las primeras décadas del siglo XX era un espacio exclusivo de los hombres ${ }^{91}$. Pero, a pesar de que algunos sitios estaban vedados para la mujer, ella sí podía acceder como espectadora a las conferencias que brindaban escritores e intelectuales, debido a que esta práctica cultural era considerada como un espectáculo teatral. Eso lo expone Anatole France en la "Enquête sobre la mujer argentina" en relación a la serie de conferencias sobre Rabelais que dictó en 1909 en el Teatro Odeón. El entrevistador Ibels, le

\footnotetext{
${ }^{90}$ Estas iniciativas se relacionan con el asociativismo. Como afirma Hilda Sábato en "18601920. Estado y sociedad civil”. In: AA. VV., De las Cofradias a las Organizaciones de la Sociedad Civil. Historia de la iniciativa asociativa en Argentina, $1776-1990$ (Buenos Aires: Edilab Editora, 2002), a fines del siglo XIX la mujer argentina fue cobrando mayor visibilidad en la vida pública, ya que hubo una paulatina aceptación de su intervención en instituciones y sociedades (mutuales, clubes sociales, etc.) y, porque comenzaron a formarse núcleos de mujeres dedicados a cuestiones de interés colectivo. Una de las iniciativas más importantes que se concretó en 1900 fue el Consejo Nacional de Mujeres de la República Argentina que reunía organizaciones femeninas. Las asociaciones que participaron del Consejo fueron de caridad y beneficencia, de inmigrantes, profesionales y educadoras. Vemos alli el rol activo que tomaron las mujeres a la hora de organizarse de acuerdo a sus intereses y ocupaciones.

91 El incipiente campo literario era comandado por hombres. Como analizan Carlos Altamirano y Beatriz Sarlo en su clásico capitulo "La Argentina del Centenario: Campo intelectual, vida literaria y temas ideológicos". In: Ensayos argentinos. De Sarmiento a la vanguardia (Buenos Aires: Ariel, 1997), los espacios de reunión eran el café, la redacción de diarios y revistas, la cerveceria, la librería y otros. Los lazos familiares todavia seguian siendo importantes para hacerse un lugar en el campo, pero también aparecen nuevas formas de inserción como la Universidad y el periodismo. Las mujeres no tenían lugar en este mundillo. Habrá que esperar hasta mediados de la década del '10 para que una mujer sea invitada a formar parte de los banquetes de la revista Nosotros y, que sea considerada como un igual. Ella seria Alfonsina Storni.
} 
pregunta sobre la asistencia de argentinas en sus conferencias, y France responde:

-¿Podéis dudarlo?... Pero si ellas eran las únicas que me prestaban mayor atención... Y como comprenderéis, el asunto de mis conferencias Rabelais, no era muy a propósito para cautivar la atención femenina. Además debo advertiros, que las mujeres de allá leen nuestra literatura mucho más que las de aquí. La conocen tan bien como nuestras adorables parisienses... quizás mejor... Todo cuanto procede de la Ville Lumiere les interesa (IBELS, 1910 (a), p. 65).

En esta situación también vemos una transformación, ya que de a poco, al ir cambiando la sensibilidad sobre las particularidades de la vida femenina, las mujeres podían acceder a espacios y actividades que en años anteriores sólo podían circular, presenciar y realizar los hombres.

\section{Comentarios sobre la vida femenina: manifestaciones y transformaciones}

En los textos de los viajeros que llegaron a Argentina desde Europa entre 1909 y 1914 podemos observar cómo ellos retrataron a la mujer y su vida en tres aspectos: en lo corporal, lo mental y espiritual, y en relación a su vida cotidiana y a los espacios por los que ella podía circular. En lo corporal la mujer era bella y elegante. En la mentalidad y lo espiritual, la argentina era digna, correcta y culta. El lugar central de su vida era el hogar, y para los tiempos de ocio, accedia a espacios que ya estaban determinados por la sociedad: el teatro, el hipódromo, los salones, los parques y algunas zonas comerciales y de paseo de la ciudad. Esa mujer delineada por los viajeros, es la mujer ideal que el hombre del novecientos creó, y procuró que las mismas mujeres lo internalizaran como sus cualidades naturales.

Pero, lo más notable de la mirada de los viajeros es el hecho de que pudieran advertir el afán femenino por su instrucción, no como un adorno más, sino como parte de su formación personal. Asimismo, ese deseo, no sólo fue observado por estos viajeros, sino que la voz femenina irrumpe en el relato de viaje tematizando este asunto. Para concluir, ponemos en consideración que el viajero extranjero es un sujeto que tiene la capacidad, por no pertenecer a la sociedad visitada, de vislumbrar cuestiones 
especificas. Es decir, que su mirada ajena puede ver y oír determinadas cosas y procesos que la propia sociedad no llega a discernir. Este tipo de observaciones fueron las que nos interesaron, que se evidenciaron en las descripciones sobre la vida femenina. Blasco Ibáñez, Huret, Gómez Carrillo y France relevan en sus textos algunas singularidades de la sensibilidad de la sociedad con respecto a la vida de femenina, en especial sus manifestaciones y transformaciones. Tal vez, lo más relevante es que, al igual que Buenos Aires que transitaba grandes modificaciones, los viajeros dieron cuenta de un germen de cambio en la sensibilidad argentina con respecto a los posibles horizontes femeninos.

\section{REFERENCIAS}

ALTAMIRANO, Carlos y Beatriz SARLO, La Argentina del Centenario: Campo intelectual, vida literaria y temas ideológicos. In: Ensayos argentinos. De Sarmiento a la vanguardia. Buenos Aires: Ariel, 1997.

BARRÁN, José Pedro, La mujer dominada. In: Historia de la sensibilidad en el Uruguay. Montevideo: Ediciones de la Banda Oriental, 2015.

BLASCO IBÁÑEZ, Vicente. Mi viaje a la Argentina. La Nación (Buenos Aires), domingo 11 abril de 1909.

BLASCO IBÁÑEZ, Vicente. Cómo ve Europa a América. La Nación (Buenos Aires), lunes 5 abril de 1909 (a).

BLASCO IBÁÑEZ, Vicente. La Argentina y sus grandezas. Valencia: Prometeo, 1910.

GÁlVEZ, Manuel. El mal metafísico. Vida romántica. Buenos Aires: Espasa Calpe, 1947.

GÓMEZ CARRILLO, Enrique. El encanto de Buenos Aires. Madrid: Perlado, Páez y Compañía, 1914.

HURET, Jules, La Argentina. De Buenos Aires al Gran Chaco. París: Louis Michaud, 1911. 
HURET, Jules. La Argentina. Del Plata a la Cordillera de los Andes. París: Louis Michaud, 1911 (a).

IBELS, André. Enquête sobre la mujer argentina. La opinión de Blasco Ibáñez. Gustos y gestos (París), 1º de septiembre de 1910.

IBELS, André. Enquête sobre la mujer argentina. La opinión de Anatole France. Gustos y gestos (París), 1º de octubre de 1910 (a).

LOSADA, Leandro. La alta sociedad en la Buenos Aires de la 'Belle Époque'. Sociabilidad, estilos de vida e identidades. Buenos Aires: Siglo XXI, 2008.

PIERINI, Margarita. Viajeros europeos en la Buenos Aires del Centenario. In: Derroteros del viaje en la cultura: mito, historia y discurso. eds. Sandra Fernández, Patricio Geli y Margarita Pierini. Rosario: Prohistoria, 2008.

SÁBATO, Hilda. 1860-1920. Estado y sociedad civil. In: AA. VV., De las Cofradias a las Organizaciones de la Sociedad Civil. Historia de la iniciativa asociativa en Argentina, 1776-1990. Buenos Aires: Edilab Editora, 2002.

Recebido em: 15/06/2016

Aceito em: 21/07/2016 